Article

\title{
Flood-Resilient Communities: How We Can Encourage Adaptive Behaviour Through Smart Tools in Public-Private Interaction
}

\author{
Peter R. Davids ${ }^{1, *}$ and Thomas Thaler ${ }^{2}$ \\ ${ }^{1}$ Center for Mobility and Spatial Planning, Ghent University, Belgium; E-Mail: peter.davids@ugent.be \\ 2 Institute of Mountain Risk Engineering, University of Natural Resources and Life Sciences, Austria; \\ E-Mail: thomas.thaler@boku.ac.at \\ * Corresponding author
}

Submitted: 3 March 2021 | Accepted: 28 April 2021 | Published: 19 August 2021

\begin{abstract}
To achieve a more flood-resilient society, it is essential to involve citizens. Therefore, new instruments, such as tailor-made advice for homeowners, are being developed to inform homeowners about adaptive strategies in building to motivate them to implement these measures. This article evaluates if public-private interactions, such as tailored advice, change risk behaviour and therefore increase flood resilience among homeowners. The article conducted semi-structured interviews with homeowners who had received advice as well as involved experts in two case study regions in Europe: Flanders in Belgium and Vorarlberg in Austria. The results show how the tailored advice helps homeowners who are already aware of flood risks and provides them with answers on how to adapt a house. However, the tool seems to lack the ability to inform and "recruit" new groups of homeowners who are not as familiar with flood risks. As such, this article concludes that this initiative has a relatively low impact in raising flood risk awareness among homeowners but may be more successful in serving as a tool that suggests tailored property-level flood risk adaptation measures for those who are already aware. Alternatively, more automated tailored information systems might be more efficient for unaware homeowners.
\end{abstract}

\section{Keywords}

Austria; Belgium; flood risk management; homeowners; property level flood risk adaptation (PLFRA); risk governance; tailored risk communication

\section{Issue}

This article is part of the issue "Smart Urban Governance for Climate Change Adaptation" edited by Thomas Thaler (University of Natural Resources and Life Sciences, Austria), Patrick Witte (Utrecht University, The Netherlands), Thomas Hartmann (TU Dortmund University, Germany) and Stan Geertman (Utrecht University, The Netherlands).

(C) 2021 by the authors; licensee Cogitatio (Lisbon, Portugal). This article is licensed under a Creative Commons Attribution 4.0 International License (CC BY).

\section{Introduction: A Behavioural Turn in Flood Risk Management}

Flood hazards that are caused due to exceptional rainfall events lead to severe damage in European urban areas (Alfieri et al., 2015; Field et al., 2012), and climate models predict an increase of such events in the coming decades (Intergovernmental Panel on Climate Change, 2018). Governments traditionally try to reduce the probability of flood events with solutions such as dikes and other technical solutions. However, the increase and unpredictability of floods leads to an increased complex- ity of flood risk management, as governments can no longer guarantee "dry feet" for their citizens based on governmental interventions (Meijerink \& Dicke, 2008; Rauter et al., 2020). Based on the principles of resilience (Fekete et al., 2020; Folke et al., 2010; Liao, 2012), governments in the present day strive for a more holistic riskbased approach that includes uncertainties (Kuklicke \& Demeritt, 2016), planning (Hartmann \& Juepner, 2014), and the involvement of civil actors (Forrest et al., 2020; Seebauer \& Babcicky, 2018). These new actors, such as homeowners, are becoming part of flood risk management as they can reduce their personal vulnerability 
(e.g., Kuhlicke et al., 2020; Mees et al., 2016; Rufat et al., 2020; Snel et al., 2020). Consequently, flood risk management requires collaborative planning for public administration. Sharing responsibility is becoming more and more common (Begg et al., 2017; Butler \& Pidgeon, 2011). Influenced by these developments, flood risk management is becoming more adaptive, flexible, and dynamic (McClymont et al., 2019). As such, new actors get involved and traditional strategies diversify with new approaches, strategies, and instruments in the field of flood risk management (Hegger et al., 2016).

New actors, such as homeowners, are asked to actively participate in flood risk management because their actions can reduce potential losses in and directly around their houses and impact their vulnerability. One of the main reasons for this change of perspectives is that the government is not able to reduce risks to zero. To reduce the remaining risks (such as residual risk or lack of structural engineering solutions to protect communities) homeowners need to contribute to the solution (Kreibich et al., 2005). Therefore, in recent years, new approaches, strategies, and instruments have appeared to inform and motivate residents about their flood risks, their responsibilities, the need for adaptation, and which things can be adapted. Examples of strategies include, among others, flood risk mapping (Van Alphen et al., 2009), participatory projects (Begg, 2018), inter-regional co-operation (Thaler et al., 2016), and strategies to target direct or indirect implementation of property level flood risk adaptation (PLFRA, which includes (1) wet-proofingcontrolled flooding and the adaptation of interiors, (2) the avoidance of flooding-e.g., stilts or floating structures, and (3) dry flood-proofing-e.g., watertight basement windows, etc.; Attems, Thaler, Genovese, et al., 2020; Gersonius et al., 2008). Among individual homeowners, strategies include recovery financing linked to future damage reduction (Slavíková et al., 2021), flood labelling for houses (Hartmann \& Scheibel, 2016), a duty to inform during housing transactions (Mees et al., 2018), and tailored expert advice for homeowners (Davids et al., 2019). All these strategies can contribute to a behavioural turn among citizens in flood risk management (Kuhlicke et al., 2020), as these strategies: (1) try to understand and influence the willingness to act, (2) inform about the effectiveness of PLFRA measures, and (3) support homeowners on the implementation of these measures. For example, a homeowner could reduce potential damage by removing valuable furniture or moving the kitchen from the basement to the first floor, or by the installation of bulkheads and pumps. Moreover, based on an effectiveness/efficiency analysis, sometimes interventions at the local level (for example in residential buildings) are preferred over extensive spatial interventions (Hoss et al., 2011; Kaufmann et al., 2016). Consequently, this makes flood risk management no longer a solely governmental activity, as citizens can have an active role using PLFRA measures and therefore reduce flood damage (Mees et al., 2016; White et al., 2018). However, the uptake of these measures by homeowners is still low (Attems, Thaler, Genovese, et al., 2020; Grothmann \& Reusswig, 2006; Kellens et al., 2013; Rözer et al., 2016). There are various explanations as to why homeowners still refuse or struggle to implement PLFRA measures. One key problem is that homeowners are not always aware of their flood risks (Thistlethwaite et al., 2018). Further, homeowners often lack information on how to implement PLFRA measures in their houses (Attems, Schlögl, et al., 2020). Aside from that, homeowners often seem unwilling to take measures as they perceive flood risk management as a governmental task or they do not have the legal rights, know-how, or financial savings to implement PLFRA measures (Botzen et al., 2013; Bubeck et al., 2012; White et al., 2018). So, there is a gap: Governments expect homeowners to participate in local flood risk management, but these homeowners are not always conscious or able to or willing to change their behaviour. This lock-in situation between government and homeowners is happening more often, and more interactive and collaborative approaches in risk communication are desired (Mees et al., 2018; Tasantab et al., 2020). The aim of the article is to address if new instruments in risk communication, such as using smart technologies, are more effective in informing and encouraging homeowners of how to implement PLFRA measures at home. An example of such smart technologies is tailored advice for homeowners. This is a tool to evaluate flood risk levels at home and provides suggestions to reduce these risks with solutions tailored to the characteristics of a specific home. As such, this tool seems to focus more on providing information and triggering adaptive behaviour than on awarenessraising. These suggestions can be automatically calculated, and in some cases additionally explained by a flood risk expert. Such smart technologies have become a more crucial aspect in flood risk management in the past few years (Neubert et al., 2016; Ran \& Nedovic-Budic, 2016; Schinke et al., 2013). Smart technologies in flood risk management include two directions: (1) the innovation of new technologies in terms of PLFRA measures (White et al., 2018) and (2) information and communications technology (ICT), such as the use of artificial intelligence or new forms of communication (Attems, Thaler, Snel, et al., 2020; Kratzert et al., 2019). The advantages of using smart technologies in flood risk management are the ability to use the latest ICT innovation to reach a wide range of different people with a standardised approach (Jiang et al., 2020a, 2020b). The literature addresses the advantages of smart technologies in terms of including multiple actors at multiple political levels as well as the ability to interact within these smart technologies (Kummitha \& Crutzen, 2017; Neirotti et al., 2014). There are various examples of using smart technologies in urban planning (see, e.g., Geertman \& Stillwell, 2020). Nevertheless, the use of smart technologies highly depends on the willingness of people to accept and interact with the tools (Greenfield, 2013). In addition, the tools often lack certain flexibility within the design level 
to include the special needs of communities. For example, the housing stock in Belgium, Germany, Austria, or Switzerland shows more variety due to their individualistic designs and constructions, compared to the uniform prefabricated housing stock in countries such as the Netherlands and the UK. These varieties among individual houses result in more specific questions on risk reductions among the homeowners.

To explain if smart technologies such as tailored advice are more effective in informing and encouraging homeowners, and to analyse what factors influence the level of success of the pilots, this article uses Boelens' (2018) actor-relational approach. The actor-relational approach provides a wider perspective of spatial planning actions. The framework includes "other forms of independent action, within the business sector, the institutional community, and in everyday life" (Boelens, 2020, p. 11). This approach is able to analyse the relations and co-evolutionary interaction among factors, actors, and institutions, instead of the factors, actors, and institutions themselves (Boelens, 2010; Boelens \& de Roo, 2016). When considering behavioural change of homeowners in flood risk management, we need to also consider changing behaviour of other actors and contextual factors (Davids et al., 2019). This approach offers the opportunity to analyse how tailored advice leads to institutional innovation and more specifically, to behavioural change. Therefore, in the next section and based on the structure of factors, actors, and institutions, this article considers the following research questions:

- Which contextual factors, actors, and institutions determine the use of smart technologies, such as tailored advice, in flood risk management?

- Can tailored advice encourage a behavioural change of homeowners to increase their resilience to flood hazards?

- To what extent does tailored advice result in improved community resilience at a larger scale?

In this article, we compare two international cases of these tailored advice practises, as examples of new smart technologies because it combines standardised methodologies with in-depth analyses of a house. In Belgium, we will consider a pilot that has been running in the region of Flanders, organised by the Flanders Environmental Agency. In Austria, we consider the pilot from the region Vorarlberg, organised by the regional authority in close cooperation with blue light organisations, such as the fire brigade, and insurance sector. Whereas the Belgian experiment is considered to be successful and is starting a third pilot in 2020-2021, the Austrian experiment was mostly suspended after one pilot. We are wondering what factors influence the level of success of the pilots and what factors are limiting. Here, we assume contextual factors make a difference. To clarify this statement, we will use the actor-relational approach on tailored expert advice in flood risk management.

\section{Flood Risk Management as a Relational System}

Behavioural change of homeowners in flood risk management can be considered as highly dependent on social and institutional contexts. Therefore, homeowner involvement in flood risk management is highly relational (Davids et al., 2019). The theoretical starting point of this article forms Luhmann's (1995) systems theory of social innovation. One cannot observe a society from the outside in its totality, only from within. However, perceived from within, these observations are too complex, interactive, and volatile. To reduce the complexity, Luhmann's distinct subsystems each have their own codes of conduct, behaviours, actors, and contexts. These interact and shape the subsystem, but also interact with other subsystems, forming a relational system where interactions cause new interactions. Through these interactions a subsystem evolves and evolves and evolves, and, as such, is always in a state of becoming (Boelens \& de Roo, 2016). This leads to multiple institutional innovations happening in various directions and all happening at the same time: expanding, renewing, and innovating over and over as adaptions on the existing context (Boelens, 2018). To grasp this black box of evaluating institutions, Boelens (2018) distinguishes factors of importance, actors, and institutions that co-evolve together (see Figure 1):

- Factors of importance include elements such as geography and infrastructure. In the subsystem of flood risk management, examples of these factors include climate change, floods, risk, and the availability of structural and PLFRA measures.

- Institutions are the formal and informal codes of conduct in a subsystem. In the subsystem of flood risk management, examples include agreements on responsibility and accepted levels of residual risk.

- (Leading) actors of a subsystem include governmental, business, and civil actors. In the subsystem of flood risk management, examples include governmental flood risk managers, local leaders of citizen groups, insurers, and companies involved in PLFRA implementations.

Together, these three components and their interactions shape subsystems as we know them but are also able to interpenetrate or irritate other subsystems, which in turn can innovate and evolve (Boelens, 2018).

This system of co-evolutions is one that we recognize in flood risk management as well. As the system of flood risk management is facing more floods that have left more damage over the past few decades (new factors of importance), governments make an appeal to homeowners to take responsibility for their houses (new leading actors are invited to participate). Also, new formal and informal agreements are formed to share the responsibility of flood risk (new institutions). These innovations 


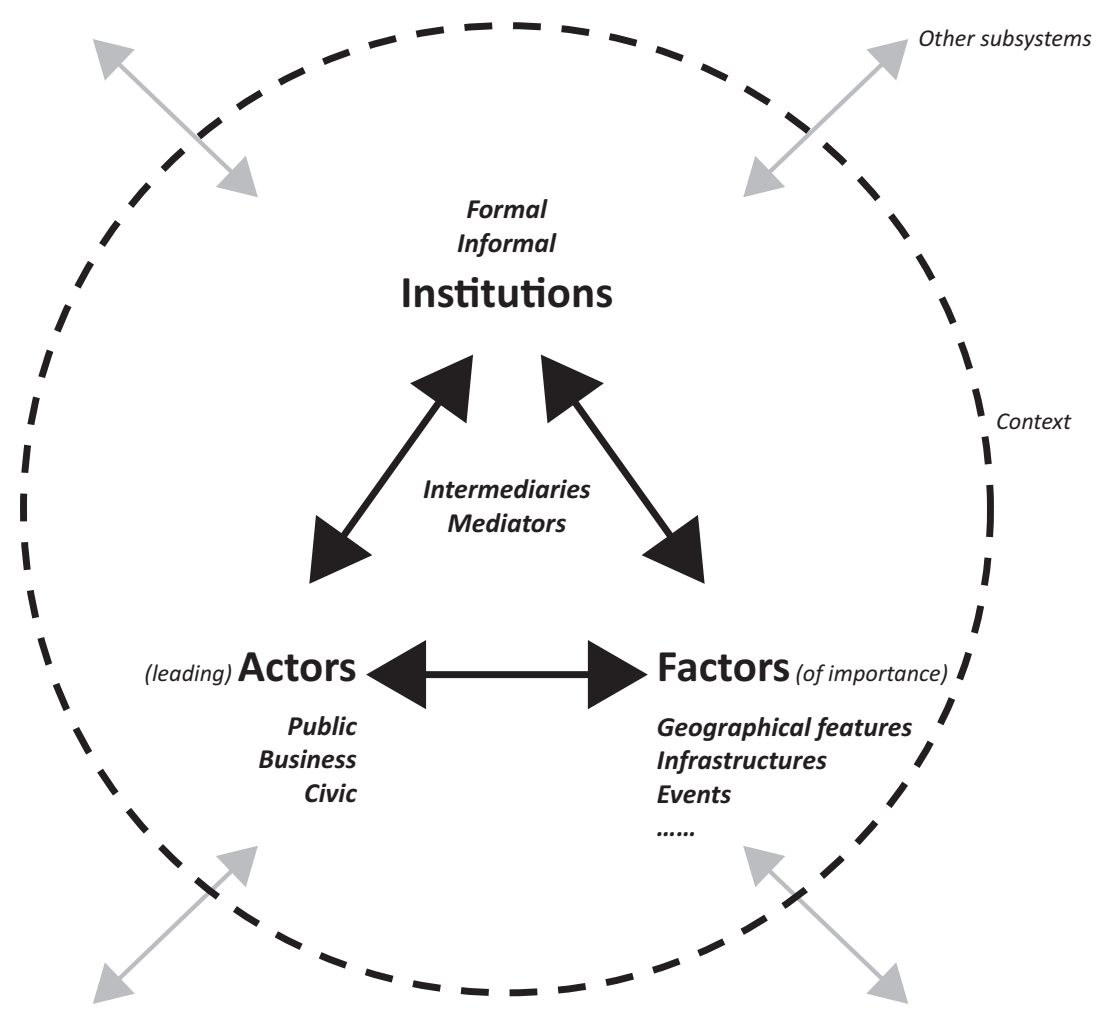

Figure 1. Scheme of an actor-relational subsystem. Source: Boelens (2018, p. 96).

influence each other back and forth and result in a new evolution being born.

Influencing this continuous interactive evolution is complex. The outcome of interventions cannot be predicted and directed due to the volatile and dynamic nature of the interactions. However, Healey (2007) highlights how, in this case, flood risk managers should be skilled to take the pulse of these interactive dynamics and generate opportunities for encounters. This is where tailored advice comes in, which can, in line with Boelens (2018), perform as an intermediary, transferring knowledge without changing it, or as a mediator, translating and aligning information mutually between factors, actors, and institutions, resulting in institutional innovation, in this case, a change of behaviour within the system. Using the actor-relational approach makes it possible to analyse the role of specific smart tools in the complexity of interrelations of flood risk management.

\section{Methods}

This article used a mixed-method design combining semistructured interviews with national and regional authorities and citizens, analysis of policy documents, as well as phone interviews with citizens.

For the first study site in three towns in Flanders (Belgium), we conducted in total 14 semi-structured indepth interviews; one interview with the project leader of the Flanders Environment Agency responsible for the pilot; and 13 interviews with homeowners that participated in the pilot. Homeowners were randomly selected in the experts' agenda and interviews took place directly after the visit of experts. The semi-structured interviewees were conducted in June and July 2017 and lasted between 60 and 75 minutes. Additionally, among all 209 participating homeowners a short telephone survey was executed. For this survey, a total of 175 out of 209 project participants were contacted. From these, 148 were willing to participate in the short telephone survey. The phone calls took about 10 minutes.

In the second study site of Vorarlberg (Austria), we conducted in total 18 semi-structured in-depth interviews; two interviews at the national level with experts from the national flood risk management policy, two experts at the regional level responsible for the implementation of the regional flood risk management strategy in the federal state of Vorarlberg, 12 interviews with homeowners, as well as two stakeholders from insurance and blue light organisations. The selection process of the sampling was one sided, based on the network between the researcher and researched as well as a snowball effect to recruit the sampling of the homeowners (Rauter et al., 2020). The semi-structured interviews were conducted between February and May 2018 and lasted between 30 and 120 minutes. The interviews were transcribed and coded within the software package f4 and NVivo.

For both studies, the themes that were covered in the interviews included experiences of past flood event(s), key actors in flood risk management, the role of various actors, barriers and drivers of the implementation of PLFRA, trigger points to implement PLFRA, interactions 
with governmental actors and neighbourhoods (i.e., process, type of communication), funding (e.g., financial subsidies, bank loans, etc.), legal obligations and restrictions, reflections on the communication between homeowner and expert, and the role of ICT in the process.

For both studies, we used a grounded theoretical approach to analyse the interviewees, where the code was structured around the actor-relational approach by Boelens (2018). Moreover, we analysed the national and regional policy documents dealing with the implementation of the PLFRA measures as well as the regional and local legal regulations, such as planning, building codes, and emergency management. The aim of the policy analysis is to understand how the institutional framework is framed in both countries and how the two different institutional frameworks influence the use of smart technologies in flood risk management (Thaler et al., 2020; Wildavsky, 1969).

\section{Results}

\subsection{Factors}

The towns of Sint-Pieters-Leeuw, Geraardsbergen, and Lebbeke are located in the region of Flanders, in the Dender and Zenne valleys, west of Brussels. Situated in the urban fringe of Brussels, the towns attract citizens from the capital looking for cheaper private-owned single-family detached and semi-detached housing in a green environment. The combination of a hilly landscape, and an erosion-prone soil of sand and loam, ensures rapid precipitation drainage, and makes the areas vulnerable to pluvial flooding. Despite the presence of retention basins, these basins appear to be too small to prevent flooding throughout the whole valley in the case of extreme precipitation. Recent exceptional rain showers (e.g., 2010, 2014, and 2016) resulted in incoming water in underground garages or at ground floor level, damaging up to 600 houses in Sint-Pieters-Leeuw during the 2010 flood (Hydroscan, 2018). The main causes included rainwater runoff, the overflow of the local river, or the backflow of water from the public sewer. To reduce future damage, some homeowners had already implemented some provisional PLFRA measures.

The federal state of Vorarlberg is characterised as a rural/peri-urban region with a wide range of privateowned single-family detached buildings. The federal state is located in the western part of Austria, close to the countries of Germany, Liechtenstein, and Switzerland, where a large proportion of citizens commute to work as the average earnings are higher in comparison to Vorarlberg. The region also includes a high density of manufacturers, especially in the Rhine and Walgau valley. Before the Covid-19 pandemic, the region had strong economic growth rates, which attracted a high number of national and international citizens to relocate to the region. Further, the Walgau valley connects the main transport lines to Switzerland. However, a large number of the residential and non-residential buildings can be found in floodplain areas, due to a lack of permanent settlement and economic prospective within the region. Mountain communities, such as in the Bregenzerwald, show a marked decline of the population and an increase of second-home residents. Consequently, Vorarlberg was affected by several flood events in the past 20 years, such as river floods, torrential floods, debris flow, surface runoff, or groundwater flooding. In particular, the 2005 flood event caused high economic losses in the region as well as new policy concepts as a response to the event, such as encouragement of the implementation of PLFRA.

\subsection{Actors}

In federally organised Belgium, flood risk management is predominantly regionally organised. Only emergency planning and recovery and insurance policy are organised on a national level. For the management of floods, the region of Flanders distinguishes responsibility based on navigability of waters. Navigable waters are a responsibility of the regional Department of Mobility and Public Works; flood alleviation in non-navigable water is a responsibility of Flanders Environment Agency. Coordination between these two departments and municipal, provincial, and regional actors is organised by the Commission on Integrated Water Policy. Flood recovery compensation after a flood event is covered in household or fire insurance. If the insurance is not covered (e.g., when a flood is acknowledged as national disaster), homeowners can submit a claim with the federal disaster fund, and decisions on disbursements are made on a regional level.

As these governmental actors are not always able to prevent flooding, Flanders Environment Agency funds and organises tailored expert advice for homeowners to motivate the implementation of PLFRA. The case study that is considered for this article entails a pilot among 210 homeowners that ran from 2017 to 2018 in the municipalities of Sint-Pieters-Leeuw, Lebbeke, and Geraardsbergen. Previously, between 2013 and 2015, a first pilot ran among 85 homeowners living in Beersel and Sint-Genesius-Rode. A third pilot to advise about 150 households will be running in the town of Moelingen, and in municipalities along the brooks of Zwalmbeek and Kerkebeek in 2020 and 2021.

The Flanders Environment Agency uses an active strategy to recruit participants. This recruitment campaign started with an invitation letter that was sent out to everyone in flood-prone areas within the municipality as well as announcements in local newspapers. In both the letter and announcement, a reference to a website was made providing background information on the project and project process. The website also provided registration for a first general meeting in the community centre. Besides personal details, the registrant had to provide information on their flood risk experience and tenure status. From the $300+$ registrations, the agency 
selected 210 homeowners that suffered the most based on recent flood data from the fire brigade.

The advising process included a meeting between a homeowner and two experts at home. One expert has a background in loss-adjusting for insurance, and the second has expertise in urban water management. During a house visit, the experts collected data for the final report, which contained information on recent flood damage, building features, position of the house on flood risk maps, insurer details, overview of measures already taken, photos of the house and surroundings, and a list of proposed PLFRA measures and an estimation of the costs. In a final meeting between homeowner and experts in the city hall, these final reports were presented, clarified, and discussed between the expert and homeowner. In most cases the experts advised on the introduction of a pump to remove incoming water, floodwalls, backup valves, or a combination of these mentioned PLFRA measures. The estimated costs varied considerably from $€ 500-600$ for simple interventions such as a backup valve, and up to tens of thousands of euros for more complicated solutions. Almost half of the participants implemented (at least partially) the experts' advice on PLFRA: $32 \%$ from selected sampling implemented some PLFRA and $15 \%$ from selected sampling implemented all suggested PLFRA. Some homeowners have not yet implemented any PLFRA, but are still planning to, and a minority of homeowners is not willing to take further action for several reasons, including the costs of PLFRA and age of the homeowner.

The main actors in the Austrian flood risk management policy are two organisations: the national authority-Forest Engineering Service for Torrent and Avalanche Control (responsible for mountain hazards)-and the regional authority, the Federal Water Engineering Administration (responsible for river floods). Both organisations are responsible for the development of the policy framework in flood risk management, planning, and implementation of flood alleviation schemes in the region, providing hazard and risk maps, as well as contributing $80 \%$ of the costs for the realization of flood alleviation schemes. The local authorities are mainly responsible for the maintenance of flood alleviation schemes, contributing up to $20 \%$ of the costs of these, as well as for emergency management and land use management. The compensation scheme includes a mixture of private and public compensation, where the public administration provides a disaster-aid payment rate of up to $75 \%$ of the losses. The implementation of PLFRA measures is mainly in the hands of private landowners. Following the 2005 flood event, the region installed a temporary tailored expert position at the Regional Fire Brigade Association of Vorarlberg. The aim of the tailored expert position has been to inform homeowners how to implement PLFRA measures at their buildings. Initially this position was funded as a public-private partnership between public administration and the insurance sector.
Between 2013 and 2016 more than 80 homeowners received tailored advice from the Regional Fire Brigade Association of Vorarlberg. The recruitment was based on direct communications, newspapers, or presentations. Most homeowners acted on the recommendations made by insurance companies or the local fire brigade to take active PLFRA measures, others came directly to the expert based on newspaper articles, public presentations by the experts, or leaflets. However, most recruited homeowners had already implemented various PLFRA measures. A minority of homeowners implemented no further PLFRA measures after being given advice for several reasons, such as age-as some homeowners were already $70+$ and did not expect any flood event in the near future-or the homeowners had high trust in the public flood alleviation schemes. Interestingly, financial restrictions played no role in the implementation or rejection of PLFRA measures. Nevertheless, the interviews stated that only a small number of homeowners in the region showed an interest in tailored expert advice (around 80 homeowners used the ability to interact with the office). This was also a main argument why the insurance sector left the partnership after this initial period. Using other communication channels failed as the homeowners requested face-to-face interactions with the Regional Fire Brigade Association of Vorarlberg.

\subsection{Institutions}

The role of PLFRA measures plays a secondary perspective in the Austrian flood risk management policy. The key focus still lies on structural measures, such as dams or flood retention measures, across the country. The implementation of PLFRA measures (for already existing buildings) is mainly voluntary and is organised in Vorarlberg. Private property rights ensure that homeowners can freely make decisions about their property. This makes it so that public administration cannot force already existing buildings in hazard-prone areas to conduct any measures to reduce the losses from future flood hazard events. On the other hand, the public administration is also restricted by the law in providing financial subsidies to support homeowners to implement PLFRA measures. In terms of land use restrictions, the only influence is to design hazard-prone areas to avoid placing new residential and non-residential buildings in high-risk areas. Vorarlberg, for example, classifies "unfavourable natural circumstances" as a reason for land restriction, but does not provide a quantitative number, such as 1:100 (Rauter et al., 2019, p. 9). Additionally, the compensation regulation (after an event) does not provide any regulations or guidance to encourage homeowners to implement PLFRA measures (neither from insurance nor public administration). Consequently, the main activities are the provision of websites, newsletters, articles in newspapers, or public presentations by public administration that are strongly supported and managed by the tailored expertise of the Regional Fire Brigade Association of 
Vorarlberg. However, the regional policy encourages the implementation of PLFRA measures, but not as the highest priority within flood risk management. Therefore, the project with the tailored expertise in the Regional Fire Brigade Association of Vorarlberg still exists, but it is limited in its activities as the insurance sector is no longer part of the project.

In Flanders, PLFRA gained more attention since the introduction of multi-layered water safety as policy discourse in 2013. This concept is the Flemish translation of the EU Floods Directive 2007/60/EC and aims to optimally combine measures of structural defence, spatial planning, and emergency planning in order to reduce risk in the region to a minimum. This approach emphasizes a multi-actor approach and suggests active involvement of water managers, spatial planners, the insurance, and construction sectors, as well as citizens. This has resulted in new tools and instruments to involve these sectors. To involve citizens, a "duty-to-inform" was introduced by the Flemish government in 2013 and indicates flood vulnerability levels of a property in real estate advertisements. For the Flanders Environment Agency, this policy discourse implies that homeowners could actively reduce residual risk, even though citizens generally expect the government to be exclusively responsible and able to avoid flood damage. Through these pilots, the agency wants to inform homeowners about this shared responsibility and about the homeowners' ability to reduce flood risks. Moreover, as flood risk maps only provide information on the plot of a houseand not on the construction of the house-and as the government cannot enforce homeowners to implement any PLFRA, the agency started the pilots on tailored advice. The project leader stipulated that in the future they would like to involve more actors, such as insurers and construction industries, to develop related incentives such as modified insurance premiums. However, involvement in these pilots is limited to a generous subsidy scheme organised by province and municipality, which covers the costs up to $90 \%$ for the participants in Sint-Pieters-Leeuw (up to a maximum of $€ 10,000$ ). Yet, even with the subsidies, interventions did not happen more frequently when compared to the other two municipalities where limited or no subsidy options were available. Tailored technical advice therefore seems to have more effect than a generic subsidy policy.

\section{Discussion and Conclusion}

Smart tools to involve homeowners in flood risk management are being developed in many countries that include tailored expert advice. These tools might be able to communicate risk and influence homeowners' behaviour (Attems, Thaler, Snel, et al., 2020). The results illustrate that homeowners become informed of risks and are encouraged to implement PLFRA, as the advice meets the characteristics of the behavioural turn (Kuhlicke et al., 2020) as well as explaining the effectiveness of PLFRA, and the experts are able to support homeowners with tailored information. The comparison of these two case studies illustrates how different selection procedurespassive in Vorarlberg, and active in Flanders-result in similar groups of homeowners, namely those with flood risk experience.

However, Davids et al. (2019) propose a more relational approach when evaluating these tools, to find out if the advice is also serving as a mediating tool. To measure and explain the success of a tool, we should not only look at the levels of PLFRA implementation but consider contextual factors as well. These instruments do not function on their own, but their success depends on a context of factors, actors, and institutions that shape flood risk management.

The results show how the introduction of tailored flood risk advice, provided by an expert both in Flanders and Vorarlberg contributed to an uptake of PLFRA measures among homeowners. Nevertheless, the Flanders Environment Agency perceives their pilots as successful, while in Austria the activities have been suspended. Factors in both countries are similar. Both regions struggle with similar floods, and similar structural measures are implemented. Actors, however, differ. In Flanders, the pilot is perceived as a learning path and should lead to the involvement of multiple actors in the long run, while in Austria the experiment started as a cooperation between public authorities and the insurance sector, where the insurance sector withdrew before the advising finished. Institutions also differ. Homeowner involvement in Flanders is directly related to the multi-layered water safety approach, while in Austria the role of PLFRA seems more perceived as "an extra." Also, the dynamic and highly fragmented flood risk governance in Flanders contributes to windows of opportunity for new developments in flood risk management in general (Mees et al., 2018), and for uptake of tailored advice as institutional innovation specifically. Austrian flood risk management, however, is more stable and does not encourage the introduction of PLFRA at all. Instead, the stability of the system predominantly supports a continuation of government-led engineered interventions that prevent flooding (Rauter et al., 2020).

Based on this comparison, this article concludes that tailored advice has a relatively low impact on raising flood risk awareness among homeowners, and it seems unable to recruit new people. As the tool only targets homeowners with high interest and some knowledge of flood risk, it seems to be more successful in serving to inform those who have specific questions and needs concerning PLFRA. As such, this tool can be perceived as successful, and it could be even more successful if the tool is perceived in a wider context that includes other actors' behaviour. Nevertheless, the impact of the tool as a stand-alone remains limited. Alternatively, more automated tailored information systems, aimed at a larger less specific public, and that are less resource intensive, might be more efficient to inform the unaware 


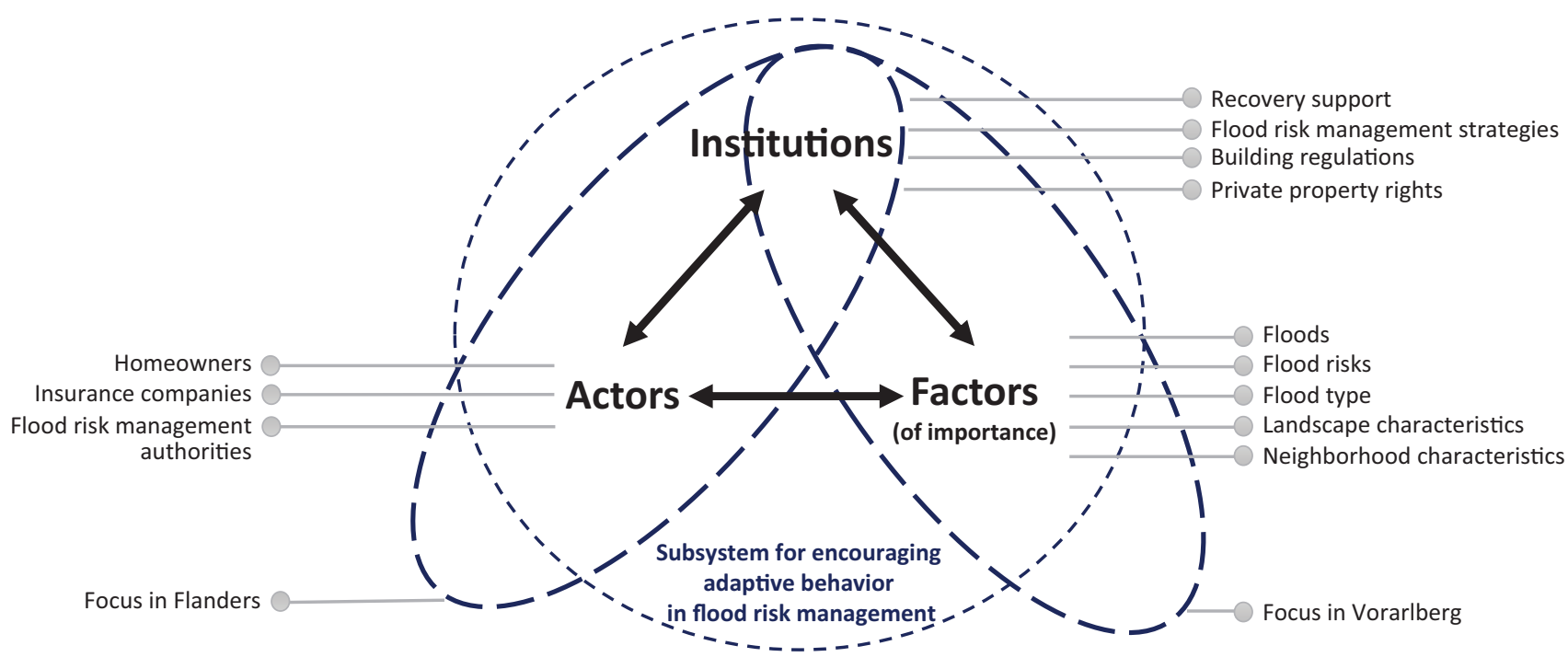

Figure 2. Scheme illustrating the dominant focus of both Flanders and Vorarlberg in encouraging adaptive behavior in flood risk management as an application of the actor-relational subsystem by Boelens (2018).

homeowners. In summary, the key question is if the costs outweigh the benefits, considering that these smart tools mostly involve and inform those who are already eager to implement PLFRA measures and not a broader target group, which is what is actually needed to reach the goal of improving the preparedness level of homeowners for future flood events. The personal interaction shows a "success" story in terms of increasing the preparedness level of the homeowners. However, this personal interaction relies heavily on face-to-face meetings, which are resource-intensive in terms of human resources, financial resources, and time needed within this process. Using a more ICT-oriented solution would not increase the behavioural turn of a larger group of homeowners as this article shows that homeowners request this face-to-face interaction.

The article adds to the current debate on how to increase flood-resilience in urban and rural communities (Fekete et al., 2020; Kuhlicke et al., 2020; Rufat et al., 2020). The focus on homeowners is essential as homeowners are a central factor in successfully reducing losses from future flood events (Attems, Thaler, Genovese, et al., 2020; Snel et al., 2020). Consequently, implementation of PLFRA measures have wide-ranging consequences for public administration and homeowners in terms of collaboration, who is responsible for what, who takes the risk of successful implementation, or who takes the lead of interacting and managing the process. Using the actor-relational subsystem helps us to understand how different factors (infrastructure, past events, geographical features), different actors (public, business, civic), and different institutional frameworks (formal and informal) influence the aim to reach a flood-resilient community. The Flanders example shows a stronger focus on the actor-institution relationship (see Figure 2).

The implementation of smart technologies is mainly driven by the institutional framework with the aim to actively involve homeowners (and other private actors in general) and implement instruments at a larger scale. Consequently, the interaction (i.e., tailored advice) between the different actors needs a strong standardised interface. In contrast, the Vorarlberg example demonstrates a focus more on the relationship between factors and institutions (see Figure 2). The 2005 flood event encourages some new instruments and frameworks in the regional flood risk management system, where the implementation of PLFRA measures mainly becomes an additional goal for the public administration. The implementation of PLFRA measures is organised and managed as public-private collaboration between regional authorities, fire brigades, and the insurance sector. Nevertheless, PLFRA strategy was always seen as an "extra" strategy as the primary goal of the Vorarlberg flood risk management strategy is still based on engineering solutions (i.e., infrastructures), such as dams or flood storage. The minor role of PLFRA is mainly defined by the existing and planned infrastructure in Vorarlberg. In summary, the co-evolutionary interaction between factors, actors, and institutions shows the politically normative dimension of flood risk management and the potential role of smart technologies in flood risk management.

\section{Acknowledgments}

This work was funded by the Austrian Research Promotion Agency (FFG) within the framework of the JPI Urban Europe project FLOODLABEL (Grant/Award Number: 693443) and Land4flood COST Action (Grant/ Award Number: CA16209). We are grateful for the cooperative participation of the interview partners, as this was the basis for this analysis. Sincere thanks go to Paul Demuth and Mathias Peter for support in interviewing households. We would also like to thank the four anonymous reviewers for their insightful comments 
on an earlier version of this manuscript. Open access funding was provided by BOKU Vienna Open Access Publishing Fund.

\section{Conflict of Interests}

The authors declare no conflict of interests.

\section{References}

Alfieri, L., Burek, P., Feyen, L., \& Forzieri, G. (2015). Global warming increases the frequency of river floods in Europe. Hydrology and Earth System Sciences, 19(5), 2247-2260.

Attems, M., Schlögl, M., Thaler, T., Rauter, M., \& Fuchs, S. (2020). Risk communication and adaptive behaviour in flood-prone areas of Austria: A Q-methodology study on opinions of affected homeowners. PloS one, 15(5), Article e0233551.

Attems, M., Thaler, T., Genovese, E., \& Fuchs, S. (2020). Implementation of property-level flood risk adaptation (PLFRA) measures: Choices and decisions. WIREs Water, 7(1), Article e1404.

Attems, M.-S., Thaler, T., Snel, K. A. W., Davids, P., Hartmann, T., \& Fuchs, S. (2020). The influence of tailored risk communication on individual adaptive behaviour. International Journal of Disaster Risk Reduction, 49, Article 101618.

Begg, C. (2018). Power, responsibility and justice: A review of local stakeholder participation in European flood risk management. Local Environment, 23(4), 383-397.

Begg, C., Ueberham, M., Masson, T., \& Kuhlicke, C. (2017). Interactions between citizen responsibilization, flood experience and household resilience: Insights from the 2013 flood in Germany. International Journal of Water Resources Development, 33(4), 591-608. https://doi.org/10.1080/07900627. 2016.1200961

Boelens, L. (2010). Theorizing practice and practising theory: Outlines for an actor-relational-approach in planning. Planning Theory, 9(1), 28-62.

Boelens, L. (2018). Moving towards a flat ontology of institutional innovation: Actor-relational lessons learned from early water management perspectives. In W. Salet (Ed.), The Routledge handbook of institutions and planning in action (pp. 92-107). Routledge.

Boelens, L. (2020). Opening up new planning landscapes: An introduction in the actor-relational approach of planning. In B. Boonstra, P. Davids, \& A. Staessen (Eds.), Opening up the planning landscape -15 years of actor-relational approaches to spatial planning in Flanders, the Netherlands and beyond (pp. 11-34). InPlanning.

Boelens, L., \& de Roo, G. (2016). Planning of undefined becoming: First encounters of planners beyond the plan. Planning Theory, 15(1), 42-67.

Botzen, W., Aerts, J., \& Van den Bergh, J. (2013). Individ- ual preferences for reducing flood risk to near zero through elevation. Mitigation and Adaptation Strategies for Global Change, 18(2), 229-244.

Bubeck, P., Botzen, W. J., \& Aerts, J. C. (2012). A review of risk perceptions and other factors that influence flood mitigation behavior. Risk Analysis: An International Journal, 32(9), 1481-1495.

Butler, C., \& Pidgeon, N. (2011). From 'flood defence' to 'flood risk management': Exploring governance, responsibility, and blame. Environment and Planning C: Government and Policy, 29(3), 533-547.

Davids, P., Boelens, L., \& Tempels, B. (2019). The effects of tailor-made flood risk advice for homeowners in Flanders, Belgium. Water International, 44(5), 539-553.

Fekete, A., Hartmann, T., \& Jüpner, R. (2020). Resilience: On-going wave or subsiding trend in flood risk research and practice? WIREs Water, 7(1), Article e1397.

Field, C. B., Barros, V., Stocker, T. F., \& Dahe, Q. (2012). Managing the risks of extreme events and disasters to advance climate change adaptation: Special report of the Intergovernmental Panel On Climate Change. Cambridge University Press.

Folke, C., Carpenter, S. R., Walker, B., Scheffer, M., Chapin, T., \& Rockström, J. (2010). Resilience thinking: Integrating resilience, adaptability and transformability. Ecology and Society, 15(4), Article 20.

Forrest, S. A., Trell, E.-M., \& Woltjer, J. (2020). Emerging citizen contributions, roles and interactions with public authorities in Dutch pluvial flood risk management. International Journal of Water Resources Development, 37, 1-23.

Geertman, S., \& Stillwell, J. (2020). Handbook of planning support science. Edward Elgar Publishing.

Gersonius, B., Zevenbergen, C., Puyan, N., \& Billah, M. (2008). Efficiency of private flood proofing of new buildings-Adapted redevelopment of a floodplain in The Netherlands. WIT Transactions on Ecology and the Environment, 118, 247-259.

Greenfield, A. (2013). Against the smart city. Do projects. Grothmann, T., \& Reusswig, F. (2006). People at risk of flooding: Why some residents take precautionary action while others do not. Natural Hazards, 38(1/2), 101-120. https://doi.org/10.1007/s11069005-8604-6

Hartmann, T., \& Juepner, R. (2014). The flood risk management plan between spatial planning and water engineering. Journal of Flood Risk Management, 10(2), 143-144.

Hartmann, T., \& Scheibel, M. (2016). Flood Label for buildings-A tool for more flood-resilient cities. E3S Web of Conferences, 7(1), Article 13006. https://doi. org/10.1051/e3sconf/20160713006

Healey, P. (2007). Urban complexity and spatial strategies: Towards a relational planning approach. Routledge.

Hegger, D. L. T., Driessen, P. P. J., Wiering, M., van 
Rijswick, H. F. M. W., Kundzewicz, Z. W., Matczak, P., Crabbé, A., Raadgever, G. T., Bakker, M. H. N., Priest, S. J., Larrue, C., \& Ek, K. (2016). Toward more flood resilience: Is a diversification of flood risk management strategies the way forward? Ecology and Society, 21(4), Article 52.

Hoss, F., Jonkman, S. N., \& Maaskant, B. (2011). A comprehensive assessment of multilayered safety in flood risk management-The Dordrecht case study. In ICFM5 Secretariat at ICHARM \& PWRI (Eds.), Proceedings of the 5th international conference on flood management (pp. 57-65).

Hydroscan. (2018). Het implementeren van individuele beschermingsmaatregelen tegen overstromingen in drie pilootgebieden. [Implementing individual protection measures against flooding in three pilot areas]. Hydroscan.

Intergovernmental Panel on Climate Change. (2018). Global warming of 1.5ㅇ. . https://www.ipcc.ch/sr15

Jiang, H., Geertman, S., \& Witte, P. (2020a). Smart urban governance: An alternative to technocratic "smartness." GeoJournal. https://doi.org/10.1007/s10708020-10326-w

Jiang, H., Geertman, S., \& Witte, P. (2020b). Smartening urban governance: An evidence-based perspective. Regional Science Policy \& Practice, 13(3), 744-758. https://doi.org/10.1111/rsp3.12304

Kaufmann, M., Mees, H., Liefferink, D., \& Crabbé, A. (2016). A game of give and take: The introduction of multi-layer (water) safety in the Netherlands and Flanders. Land Use Policy, 57, 277-286.

Kellens, W., Terpstra, T., \& De Maeyer, P. (2013). Perception and communication of flood risks: A systematic review of empirical research. Risk Analysis: An International Journal, 33(1), 24-49. https://doi.org/ 10.1111/j.1539-6924.2012.01844.x

Kratzert, F., Klotz, D., Herrnegger, M., Sampson, A. K., Hochreiter, S., \& Nearing, G. S. (2019). Toward improved predictions in ungauged basins: Exploiting the power of machine learning. Water Resources Research, 55(12), 11344-11354.

Kreibich, H., Thieken, A. H., Petrow, T., Müller, M., \& Merz, B. (2005). Flood loss reduction of private households due to building precautionary measures-Lessons learned from the Elbe flood in August 2002. Natural Hazards and Earth System Sciences, 5(1), 117-126.

Kuhlicke, C., Seebauer, S., Hudson, P., Begg, C., Bubeck, P., Dittmer, C., Grothmann, T., Heidenreich, A., Kreibich, H., Lorenz, D. F., Masson, T., Reiter, J., Thaler, T., Thieken, A. H., \& Bamberg, S. (2020). The behavioral turn in flood risk management, its assumptions and potential implications. WIRES Water, 7(3), Article e1418.

Kuklicke, C., \& Demeritt, D. (2016). Adaptive and riskbased approaches to climate change and the management of uncertainty and institutional risk: The case of future flooding in England. Global Environ- mental Change, 37, 56-68.

Kummitha, R. K. R., \& Crutzen, N. (2017). How do we understand smart cities? An evolutionary perspective. Cities, 67, 43-52.

Liao, K.-H. (2012). A theory on urban resilience to floods-A basis for alternative planning practices. Ecology and Society, 17(4), Article 48.

Luhmann, N. (1995). Social systems. Stanford University Press.

McClymont, K., Morrison, D., Beevers, L., \& Carmen, E. (2019). Flood resilience: A systematic review. Journal of Environmental Planning and Management, 63(7), 1151-1176.

Mees, H., Crabbe, A., \& Suykens, C. (2018). Belgian flood risk governance: Explaining the dynamics within a fragmented governance arrangement. Journal of Flood Risk Management, 11(3), 271-280.

Mees, H., Tempels, B., Crabbé, A., \& Boelens, L. (2016). Shifting public-private responsibilities in Flemish flood risk management. Towards a co-evolutionary approach. Land Use Policy, 57, 23-33. https://doi. org/10.1016/j.landusepol.2016.05.012

Meijerink, S., \& Dicke, W. (2008). Shifts in the publicprivate divide in flood management. International Journal of Water Resources Development, 24(4), 499-512.

Neirotti, P., De Marco, A., Cagliano, A. C., Mangano, G., \& Scorrano, F. (2014). Current trends in smart city initiatives: Some stylised facts. Cities, 38, 25-36.

Neubert, M., Naumann, T., Hennersdorf, J., \& Nikolowski, J. (2016). The geographic information system-based flood damage simulation model HOWAD. Journal of Flood Risk Management, 9(1), 36-49.

Ran, J., \& Nedovic-Budic, Z. (2016). Integrating spatial planning and flood risk management: A new conceptual framework for the spatially integrated policy infrastructure. Computers, Environment and Urban Systems, 57, 68-79.

Rauter, M., Schindeleger, A., Fuchs, S., \& Thaler, T. (2019). Deconstructing the legal framework for flood protection in Austria: Individual and state responsibilities from a planning perspective. Water International, 44(5), 571-587.

Rauter, M., Kaufmann, M., Thaler, T., \& Fuchs, S. (2020). Flood risk management in Austria: Analysing the shift in responsibility-sharing between public and private actors from a public stakeholder's perspective. Land Use Policy, 99, Article 105017.

Rözer, V., Müller, M., Bubeck, P., Kienzler, S., Thieken, A., Pech, I., Schröter, K., Buchholz, O., \& Kreibich, H. (2016). Coping with pluvial floods by private households. Water, 8(7), Article 304.

Rufat, S., Fekete, A., Armaş, I., Hartmann, T., Kuhlicke, C., Prior, T., Thaler, T., \& Wisner, B. (2020). Swimming alone? Why linking flood risk perception and behavior requires more than "it's the individual, stupid." WIREs Water, 7(5), Article e1462.

Schinke, R., Neubert, M., \& Hennersdorf, J. (2013). Mod- 
ellierung von Gebäudeschäden infolge von Grundhochwasser auf Grundlage gebäudetypologischer Untersuchungen und synthetisch ermittelter Schadensfunktionen [Modelling of building damage due to groundwater flooding on the basis of building typological investigations and synthetically determined damage functions]. Technischer und organisatorischer Hochwasserschutz-Bauwerke, Anforderungen, Modelle, 48, 365-372.

Seebauer, S., \& Babcicky, P. (2018). Trust and the communication of flood risks: Comparing the roles of local governments, volunteers in emergency services, and neighbours. Journal of Flood Risk Management, 11(3), 305-316.

Slavíková, L., Hartmann, T., \& Thaler, T. (2021). Financial schemes for resilient flood recovery. Taylor \& Francis.

Snel, K. A. W., Witte, P. A., Hartmann, T., \& Geertman, S. C. M. (2020). The shifting position of homeowners in flood resilience: From recipients to key-stakeholders. WIREs Water, 7(4), Article e1451.

Tasantab, J. C., Gajendran, T., von Meding, J., \& Maund, K. (2020). Perceptions and deeply held beliefs about responsibility for flood risk adaptation in Accra Ghana. International Journal of Disaster Resilience in the Built Environment, 11(5), 631-644.
Thaler, T. A., Priest, S. J., \& Fuchs, S. (2016). Evolving interregional co-operation in flood risk management: Distances and types of partnership approaches in Austria. Regional Environmental Change, 16(3), 841-853. https://doi.org/10.1007/s10113-015-0796-z

Thaler, T., Seebauer, S., \& Schindelegger, A. (2020). Patience, persistence and pre-signals: Policy dynamics of planned relocation in Austria. Global Environmental Change, 63, Article 102122.

Thistlethwaite, J., Henstra, D., Brown, C., \& Scott, D. (2018). How flood experience and risk perception influences protective actions and behaviours among Canadian homeowners. Environmental Management, 61(2), 197-208.

Van Alphen, J., Martini, F., Loat, R., Slomp, R., \& Passchier, R. (2009). Flood risk mapping in Europe, experiences and best practices. Journal of Flood Risk Management, 2(4), 285-292.

White, I., Connelly, A., Garvin, S., Lawson, N., \& O’Hare, P. (2018). Flood resilience technology in Europe: Identifying barriers and co-producing best practice. Journal of Flood Risk Management, 11, S468-S478.

Wildavsky, A. (1969). Rescuing policy analysis from PPBS. Public Administration Review, 29(2), 189-202.

\section{About the Authors}

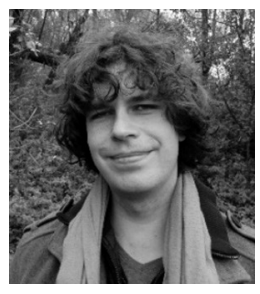

Peter R. Davids is currently finalizing his PhD-research in flood risk management at the Centre of Mobility and Spatial Planning at Ghent University. His research activities focus on flood risk management, risk governance, and marine spatial planning from a co-evolutionary perspective.

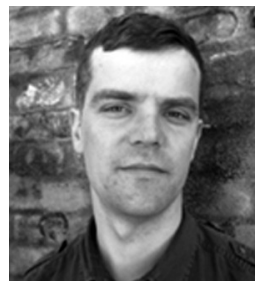

Thomas Thaler holds a PhD in Environmental Science and is currently working as a Post-Doc Researcher at the Institute of Mountain Risk Engineering at the University of Natural Resources and Life Sciences. His research and teaching activities focus on social justice, risk governance, and flood risk management. 